\title{
Chinese Herbal Medicines - Comparison of Doses Prescribed in Clinical Practice and those in China Pharmacopeia
}

\author{
Sheng-Lou $\mathrm{Ni}^{1}$, Chuan-Rong Chen ${ }^{1}$, Yan-Ling $\mathrm{Fu}^{2 *}$, Lin Zhang ${ }^{1}$ and Jia Song ${ }^{1}$ \\ ${ }^{1}$ School of Basic Medical Sciences, ${ }^{2}$ School of Continuing Education, Beijing University of Chinese Medicine, No. 11 Bei San \\ Huan Dong Lu, Beijing 100029, China
}

*For correspondence: Email: fuyanlingbucm@126.com; Tel: (+86) 10-6428-6307; Fax: (+86) 10-6422-0858

\begin{abstract}
Purpose: To compare the optimum doses of frequently used Chinese herbal medicines in clinical practice with stipulated doses in China Pharmacopoeia 2010, and assess the factors influencing choice of dose.

Methods: A total of 303 practitioners of traditional Chinese Medicine (TCM) from 50 comprehensive TCM hospitals were investigated using a multi-stage randomized questionnaire. The content of the questionnaire included doses of frequently-used Chinese herbs, cognition of current doses in clinical practice, and doctors' (practitioners') opinions on dose levels. The median of Chinese herbal medicines' dose prescribed by the participants was compared with the upper limit value (ULV) of stipulated doses in China Pharmacopoeia by assigned rank test. The centralized tendency of dose selection by TCM doctors was expressed as mean \pm standard deviation. The top three factors influencing selection of dose were obtained using inclusion and exclusion criteria.

Results: Among the selected Chinese herbs, the doses of 32 herbs exceeded ULV of the pharmacopoeia, accounting for $57.14 \%$ (32/56). The top three factors influencing dose choice were variety and quality of the herbs, mode of preparation, and herbal combination. Furthermore, due to varying quality of the medicinal materials, method of preparation, and clinical experience, the doses among the 303 TCM doctors also varied considerably.

Conclusion: There is a significant difference between the doses of herbal medicines prescribed by TCM doctors and the doses stipulated in China Pharmacopoeia. In most cases, the former doses are higher.
\end{abstract}

Keywords: Chinese herbal medicines, China Pharmacopoeia, Dose selection, Multi-stage randomized questionnaire

Tropical Journal of Pharmaceutical Research is indexed by Science Citation Index (SciSearch), Scopus, International Pharmaceutical Abstract, Chemical Abstracts, Embase, Index Copernicus, EBSCO, African Index Medicus, JournalSeek, Journal Citation Reports/Science Edition, Directory of Open Access Journals (DOAJ), African Journal Online, Bioline International, Open-J-Gate and Pharmacy Abstracts

\section{INTRODUCTION}

The interest shown in traditional Chinese medicine (TCM) can partly be attributed to its therapeutic effect which also remains an outstanding issue in the further development of TCM. Key factors influencing the effect of TCM, besides syndrome differentiation and treatment, herbal combination, property of Chinese herbs, quality of medicinal, have a strong bearing on the prescribed dosage. Until a certain dosage is used, no optimum effect can be determined. Dose-effect relation is referring to the increase or decrease of herbal dosage (concentration) which will ultimately correspond to a stronger or weakened therapeutic effect [1]. 
Studies on dose-effect relationship of TCM drugs continue to rise. For example, $5 \mathrm{mg} / \mathrm{kg}$ intravenous injection of BN52021 is the optimal dosage for severe acute pancreatitis in rats. Another example is the nonlinear biosynthetic gene cluster dose effect on penicillin production by Penicillium chrysogenum [2]. However, studies of dose-effect relation in Chinese herbs started late. There are some reports on doseeffect relationship in single Chinese herbs, but rare for compound formulations used in clinical practice $[3,4]$.

Thus, objective of this study was to compare the optimum doses of frequently used Chinese herbal medicines in clinical practice with the stipulated doses in China Pharmacopoeia 2010, and assess the factors influencing choice of dose.

\section{EXPERIMENTAL}

\section{Method and range of investigation}

The applied multi-stage randomized sampling in the investigation refers to a sampling survey which is divided into two or more stages as well as randomly selects samples in the process [5]. Details of the survey are as follows: First, detailed information about comprehensive TCM hospitals in China were sourced from Associate Professor Baolin Hong at the Beijing University of Chinese Medicine who collaborated with Department of Planning and Finance, State Administration of TCM. Second, based on the administrative regions in China, all provinces and autonomous regions were classified into seven regions (Hong Kong, Taiwan and Macau were not included) incorporating North, Northeast, East, Central, South, Southwest, and Northwest China. One province or autonomous region was chosen from each of the 7 regions randomly, thus yielding 7 provinces, namely, Jiangsu, Guangdong, Henan, Shanxi, Jilin, Guizhou and Gansu. Third, based on 2011 statistics, there are 2391 comprehensive TCM hospitals in China, spread across 31 provinces and autonomous regions. Five hospitals were selected from each province or autonomous region by randomly. Finally, some member of our research group went to these selected hospitals and selected those TCM doctors that prescribe decoction in clinic. The selection was based on recommendation by doctors or the medical department of the hospital and confirmed by the head of medical department.
Ten TCM doctors were selected from each hospital for this exercise and if there were more than 10 TCM doctors meeting the criteria, the randomization was applied for the selection. If there were less than $10 \mathrm{TCM}$ doctors, all the TCM doctors in that hospital were included.

\section{Content of questionnaire}

The questionnaire was designed and validated by experts engaged in evidence-based medicine. In order to ensure the reliability and pertinence, the questionnaire was pre-tested. The contents included doses of 50 frequently-used Chinese herbs (TOP 50) by TCM doctors, cognition of current doses in clinical practice, and opinion about factors influencing dose levels were incorporated. Top 50 was screened by the following steps: First, selection of the Chinese herbs recorded in Treatise on Cold Damage (Shang Han Lun) [3] and Essentials from the Golden Cabinet (Jin Gui Yao Lue) [2] at least twice; 80 most frequently-used Chinese herbs from outpatient clinics in 11 TCM hospitals from 8 provinces or municipalities; frequency of Chinese herbs used by 20 TCM doctors who are Jing Fang practitioners based on reference to 80 most frequently-used Chinese herbs in outpatient clinics in 21 TCM hospitals from 18 provinces or municipalities [6]. Second, we omitted four Chinese herbs, namely Fructus jujubae (Da Zao), Pericarpium Citri reticulatae (Chen Pi), Rhizoma dioscoreae (Shan Yao), and Semen coicis (Yi Yi Ren) since they also belong to the category of food. Finally, we added a Chinese herb, Fructus forsythiae (Lian Qiao), which was frequently used in the past by doctors in the School of Warm Disease in Ming and Qing dynasties, as well as by current TCM doctors.

It is believed that different effects would be produced by these herbal medicines due to varying preparation methods of the herbal medicine from the same Chinese herb. Therefore, Radix astragali (Huang Qi), Radix rehmanniae (Di Huang), Rhizoma glycyrrhizae (Gan Cao), Herba ephedrae (Ma Huang), and Rhizoma rhei (Da Huang) were divided into raw and prepared medicines respectively. Furthermore, there was no distinction in ancient times between Bai Shao (Paeoniae alba) and Chi Shao (Paeoniae rubra) as collectively they were known as Shao Yao (Paeoniae). Likewise Dang Shen (Codonopsis) and Ren Shen (Rhizoma ginseng) are the same. However, the dosages of these herbs in the investigation were separately calculated. 
Table 1: Fifty six Chinese herbs, with their botanical names, used in TCM

\begin{tabular}{|c|c|c|c|c|c|}
\hline No. & Botanical name & $\begin{array}{l}\text { Chinese name } \\
\text { (abbreviation) }\end{array}$ & No. & Botanical name & $\begin{array}{l}\text { Chinese name } \\
\text { (abbreviation) }\end{array}$ \\
\hline 1 & Aconiti lateralis & Zhi fu zi (ZFZ) & 2 & Rhizoma asari & Xi Xin (XX) \\
\hline 3 & Rhizoma zingiberis & Gan Jiang (GJ) & 4 & Zingiberis recens & Sheng Jiang (SJ) \\
\hline 5 & Ramulus cinnamomi & Gui Zhi (GZ) & 6 & Atractylodis macrocephal & Bai Zhu (BZ) \\
\hline 7 & Fructus forsythiae & Lian Qiao (LQ) & 8 & Semen persicae & Tao Ren (TR) \\
\hline 9 & Rhizoma pinelliae & Ban Xia (BX) & 10 & $\begin{array}{l}\text { Fritillariae thunbergii } \\
\text { Bulbus }\end{array}$ & Zhe Bei Mu (ZBM) \\
\hline 11 & Phellodendri chinen & Huang Bai (HB) & 12 & Fructus gardenia & Zhi Zi,(ZZ) \\
\hline 13 & Fructus trichosanthi & Gua Lou (GL) & 14 & Cortex fraxini & Qin Pi (QP) \\
\hline 15 & Rhizoma anemarrhe & Zhi Mu (ZM) & 16 & Radix ophiopogonis & Mai Dong (MD) \\
\hline 17 & $\begin{array}{l}\text { Radix } \\
\text { saposhnikoviae }\end{array}$ & Fang Feng (FF) & 18 & $\begin{array}{l}\text { Schisandrae chinensis } \\
\text { Fructus }\end{array}$ & Wu Wei Zi (WWZ) \\
\hline 19 & Radix Bupleuri & Chai Hu (CH) & 20 & Angelicae sinensis & Dang Gui (DG), \\
\hline 21 & Paeoniae rubra & Chi Shao (CS) & 22 & Paeoniae alba & Bai Shao (BS), \\
\hline 23 & Radix codonopsis & Dang Shen (DS) & 24 & Radix et Rhizoma ginseng & Ren Shen (RS), \\
\hline 25 & Radix trichosanthis & Tian Hua Fen (THF) & 26 & Cortex moutan & Mu Dan Pi (MDP) \\
\hline 27 & Rhizoma alismatis & Ze Xie $(Z X)$ & 28 & Ziziphi spinosae Semen & $\begin{array}{l}\text { Suan Zao Ren } \\
\text { (SZR) }\end{array}$ \\
\hline 29 & Polyporus sativa & Zhu Ling (ZL) & 30 & Rhizoma chuanxiong & Chuan Xion (CX) \\
\hline 31 & Radix astragali & Huang Qi $\left(H Q^{1}\right)$ & 32 & $\begin{array}{l}\text { Astragali praeparata Radix } \\
\text { cum Melle }\end{array}$ & $\begin{array}{l}\text { Zhi Huang Qi } \\
\text { (ZHQ) }\end{array}$ \\
\hline 33 & Poria mesoua & Fu Ling (FL) & 34 & Rhizoma Cimicifugae & Sheng Ma (SM) \\
\hline 35 & Radix platycodonis & Jie Geng (JG) & 36 & $\begin{array}{l}\text { Radix Rehmanniae } \\
\text { Praeparata }\end{array}$ & $\begin{array}{l}\text { Shu Di Huang } \\
\left(\mathrm{SDH}^{1}\right)\end{array}$ \\
\hline 37 & Radix rehmanniae & Di Huang $\left(\mathrm{DH}^{1}\right)$ & 38 & Rhizoma belamcandae & She Gan (SG) \\
\hline 39 & Talcum rusa & Hua Shi (HS) & 40 & Concha ostreae & Mu Li (ML) \\
\hline 41 & Stephaniae tetrandra & Fang Ji (FJ) & 42 & Herba artemisiae & Yin Chen (YC) \\
\hline 43 & Fructus evodiae & Wu Zhu Yu (WZY) & 44 & Puerariae lobatae & Ge Gen (GG) \\
\hline 45 & Radix scutellariae & Huang Qin $\left(\mathrm{HQ}^{2}\right)$ & 46 & Rhizoma coptidis & Huang Lian (HL) \\
\hline 47 & $\begin{array}{l}\text { Radix et Rhizoma } \\
\text { glycyrrhizae }\end{array}$ & Gan Cao (GC) & 48 & $\begin{array}{l}\text { Radix et Rhizoma } \\
\text { glycyrrhizae Praeparata }\end{array}$ & $\begin{array}{l}\text { Zhi Gan Cao } \\
\text { (ZGC) }\end{array}$ \\
\hline 49 & Herba ephedrae & Ma Huang $(\mathrm{MH})$ & 50 & Prepared Herba ephedrae & $\begin{array}{l}\text { Zhi Ma Huang } \\
(\mathrm{ZMH})\end{array}$ \\
\hline 51 & $\begin{array}{l}\text { Armeniacae amarum } \\
\text { Semen }\end{array}$ & Xing Ren (XR) & 52 & Gypsum fibrosum & $\begin{array}{l}\text { Sheng Shi Gao } \\
\text { (SSG) }\end{array}$ \\
\hline 53 & Rhizoma rhei & Da Huang $\left(\mathrm{DH}^{2}\right)$ & 54 & $\begin{array}{l}\text { Prepared Radix et } \\
\text { Rhizoma rhei }\end{array}$ & $\begin{array}{l}\text { Shu Da Huang } \\
\left(\mathrm{SDH}^{2}\right)\end{array}$ \\
\hline 55 & Aurantii immaturus & Zhi Shi (ZS) & 56 & Magnoliae officinalis & Hou Po (HP) \\
\hline
\end{tabular}

There is no record of Fossilia ossis M. (Long Gu) in China Pharmacopoeia 2010, and so we could not make a comparison with pharmacopoeial dose. Finally, 56 Chinese herbs, as stated in Table 1, were included for statistical analysis.

\section{Inclusion and exclusion criteria}

Doctors prescribing decoctions for oral administration in comprehensive TCM hospitals were recruited. Doctors from pediatric departments were excluded, but those from combined pediatric and internal medicine departments were included as long as when they complete the questionnaire, only adult doses prescribed in the clinic were stated.

\section{Statistical analysis}

All data normality test in keeping with normal distribution were presented as "mean \pm standard deviation (SD)", while differences between upper limit value (ULV) of doses for frequently used Chinese herbs and ULV of stipulated doses in the pharmacopeia were compared by Student's ttest. In addition, the percentage of prescribed dose each herbal medicine that exceeds that in the pharmacopeia was analyzed by descriptive statistics.

The significance of factors influencing doseeffect relationship was calculated by multiple choice sorting [7]. Specifically, 9 factors were listed in columns and the selected sequence number(s) by 292 TCM who doctors completed this question were listed in the order of 1 to 9 in the corresponding column. If the influencing factor(s) was/were not selected, it was assigned " 0 ". For the rest, we assigned 9 points to the first factor, 8 points to the second one, and 1 point to the last one. Finally, the sum in each column was calculated, and the highest points was 
considered the most significant influencing factor, and so forth.

\section{RESULTS}

\section{Demographics of the selected TCM doctors}

On investigation, the demographics such as name, age, gender, title, education background, year of working in clinic, and contact information and so forth were collected (Table 2).

Table 2: Demographics of the investigated TCM doctors

\begin{tabular}{lc}
\hline Variable & Frequency (\%) \\
\hline Sex & $66.67 \%$ \\
Male & $33.33 \%$ \\
Female & \\
\hline Age & $10.23 \%$ \\
\hline$<30$ years & 24.42 \\
$30-40$ years & 31.02 \\
$40-50$ years & 22.44 \\
$50-60$ years & 11.88 \\
> 60 years & \\
\hline Title/Status & 14.19 \\
\hline Resident & 32.67 \\
Physician & 36.96 \\
Vice Director & 13.53 \\
Director & 2.64 \\
Others & \\
\hline Educational background & 5.28 \\
\hline Technical secondary school & \\
and lower & 21.45 \\
Junior college & 67.33 \\
Undergraduate & 5.94 \\
Postgraduate & \\
\hline Clinical experience & 10.56 \\
\hline < 5 years & 19.80 \\
5 - 15 years & 40.92 \\
15 - 30 years & 28.71 \\
\hline > 30 years &
\end{tabular}

ULV of frequently prescribed Chinese herbs and pharmacopoeial ULV

Among 56 Chinese herbs, there were 4 herbs containing HS, ML, GG, and ZGC whose ULV of doses didn't display statistical differences in comparison with those in the ULV of doses stipulated in pharmacopoeia. The median in 32 Chinese herbs exceeded the ULV stipulated in pharmacopeia accounting for $57.14 \%(32 / 56)$. There were 17 Chinese herbs with $5 \mathrm{~g}$ more than the ULV stipulated in the pharmacopeia in comparison with the corresponding medians, including SZR, CX, BZ, FL, TR, DH, SDH, ZBM,
ZZ, GL, YC, WZY, WWZ, CH, BS, RS, and ZX (Table 3).

\section{Proportion of TCM doctors' single herb dose that exceeds pharmacopeial dose}

There were 32 Chinese herbs which were prescribed by over $50 \%$ of the selected TCM doctors who exceeded ULVSP, accounting for $57.14 \%$ (32/56). 9 Chinese herbs including WZY, MD, WWZ, HL, BZ, DG, BX, RS, and ZX which were used by over $80 \%$ of the participated TCM doctors in comparison with those in the pharmacopeia (Table 4).

\section{TCM doctors' cognition of factors influencing dose-effect relationship}

The factors influencing dose-effect relationship are expressed using a points system in Table 5.

According to above given statistics, patient's trust and belief of persisting in taking decoction, lack of some Chinese herbs, crude medicinal materials influenced by chemical fertilizer and pesticide, patient's life style, patient's psychology and emotion, recognition and understand of the affected disease, and going for economic profit, etc. were involved in the item of "other". The rank order of the factors (Table 5) indicates that the top 3 factors are variety and quality of Chinese herbs, preparation method, and herbal combination.

\section{DISCUSSION}

The median of 32 Chinese herbs in doses exceeded the ULVSP, and 17 Chinese herbs with $5 \mathrm{~g}$ more than the ULVSP in comparison with the corresponding medians. The main reasons given by TCM doctors were poor quality of current medicinal materials accounting for $89.04 \%$, inappropriate methods of decocting and taking medicine for $47.84 \%$, and decreased ability to make a correct syndrome differentiation for $35.88 \%$. Besides, unawareness of the stipulated dose of the corresponding herbs in pharmacopeia by most of TCM doctors [8] and actuation of economic profit also need take into consideration. Meanwhile, the flexibility and arbitrariness of Chinese herbs in dosage by TCM doctors were reflected from the values of standard deviation.

Eight influencing factors together with "other" based on the existing literatures, group discussion, and experts' opinions had some representativeness. The top 3 influencing factors on dose-effect relationship were variety and 
Table 3: ULV of doses in frequently prescribed Chinese herbs and UVL stipulated in China Pharmacopeia 2010

\begin{tabular}{|c|c|c|c|c|c|c|c|c|c|}
\hline Herb & $\begin{array}{l}\text { ULV } \\
\text { SP }\end{array}$ & Mean士SD & $\mathbf{S}$ & $P$-value & Herb & $\begin{array}{l}\text { ULV } \\
\text { SP }\end{array}$ & Mean士SD & $\mathbf{S}$ & $\begin{array}{l}\boldsymbol{P} \text { - } \\
\text { value }\end{array}$ \\
\hline$\overline{Z F Z^{\Delta}}$ & 15 & $14.24 \pm 24.62$ & -8255.5 & $1 \times 10^{-4}$ & $\mathrm{SZR}^{\square}$ & 15 & $23.23 \pm 12.67$ & 11448.5 & $1 \times 10^{-4}$ \\
\hline$X X$ & 3 & $6.04 \pm 4.41$ & 10493.5 & $1 \times 10^{-4}$ & ZL & 12 & $16.86 \pm 6.54$ & 15759 & $1 \times 10^{-4}$ \\
\hline $\mathrm{GJ}^{\Delta}$ & 10 & $12.22 \pm 6.53$ & 4508 & $1 \times 10^{-4}$ & $C X^{\square}$ & 10 & $16.05 \pm 7.55$ & 13133 & $1 \times 10^{-4}$ \\
\hline$S J^{\Delta}$ & 10 & $13.48 \pm 10.75$ & 5501.5 & $1 \times 10^{-4}$ & $\mathrm{HQ}^{1 \Delta}$ & 30 & $47.50 \pm 37.94$ & 6558.5 & $1 \times 10^{-4}$ \\
\hline GZ & 10 & $13.63 \pm 6.20$ & 8617.5 & $1 \times 10^{-4}$ & $\mathrm{ZHQ}^{\Delta}$ & 30 & $38.28 \pm 31.59$ & 2865 & $1 \times 10^{-4}$ \\
\hline$B Z^{\square}$ & 12 & $23.01 \pm 18.82$ & 19594.5 & $1 \times 10^{-4}$ & $\mathrm{FL}^{\square}$ & 15 & $22.13 \pm 10.24$ & 10743.5 & $1 \times 10^{-4}$ \\
\hline $\mathrm{LQ}^{\Delta}$ & 15 & $17.51 \pm 6.77$ & 3801.5 & $1 \times 10^{-4}$ & $\mathrm{SM}^{\Delta}$ & 10 & $11.69 \pm 3.82$ & 6108.5 & $1 \times 10^{-4}$ \\
\hline $\mathrm{TR}^{\square}$ & 10 & $13.87 \pm 4.00$ & 12660 & $1 \times 10^{-4}$ & $\mathrm{DH}^{1 \sqsubset}$ & 15 & $23.33 \pm 12.69$ & 10309 & $1 \times 10^{-4}$ \\
\hline $\mathrm{BX}$ & 9 & $13.41 \pm 5.35$ & 19799 & $1 \times 10^{-4}$ & $\mathrm{SDH}^{1 \square}$ & 15 & $24.32 \pm 13.02$ & 12632.5 & $1 \times 10^{-4}$ \\
\hline $\mathrm{ZBM}^{\square}$ & 10 & $14.88 \pm 5.22$ & 13202 & $1 \times 10^{-4}$ & SG & 10 & $12.44 \pm 3.46$ & 8224.5 & $1 \times 10^{-4}$ \\
\hline $\mathrm{HB}$ & 12 & $14.73 \pm 6.32$ & 12352.5 & $1 \times 10^{-4}$ & $\mathrm{HS}^{* \Delta}$ & 20 & $20.29 \pm 10.47$ & 335 & 0.759 \\
\hline $\mathrm{ZZ}^{\square}$ & 10 & $14.07 \pm 4.52$ & 12486.5 & $1 \times 10^{-4}$ & $\mathrm{ML}^{* \Delta}$ & 30 & $29.13 \pm 11.15$ & -517.5 & 0.146 \\
\hline $\mathrm{GL}^{\square}$ & 15 & $19.74 \pm 7.83$ & 8079.5 & $1 \times 10^{-4}$ & FJ & 10 & $13.55 \pm 4.34$ & 11286.5 & $1 \times 10^{-4}$ \\
\hline $\mathrm{QP}^{\Delta}$ & 12 & $13.12 \pm 4.33$ & 7238.5 & $1 \times 10^{-4}$ & $Y C^{\square}$ & 15 & $26.49 \pm 15.82$ & 13196.5 & $1 \times 10^{-4}$ \\
\hline ZM & 12 & $15.12 \pm 4.92$ & 13819.5 & $1 \times 10^{-4}$ & $W Z Y^{\square}$ & 5 & $11.55 \pm 5.73$ & 18899 & $1 \times 10^{-4}$ \\
\hline MD & 12 & $19.58 \pm 8.48$ & 19275 & $1 \times 10^{-4}$ & $\mathrm{GG}^{* \Delta}$ & 15 & $15.53 \pm 6.63$ & -357 & 0.636 \\
\hline $\mathrm{FF}$ & 10 & $13.48 \pm 3.86$ & 10804.5 & $1 \times 10^{-4}$ & $\mathrm{HQ}^{2 \Delta}$ & 10 & $11.63 \pm 3.28$ & 5092.5 & $1 \times 10^{-4}$ \\
\hline WWZ & 6 & $14.90 \pm 7.69$ & 21520.5 & $1 \times 10^{-4}$ & $\mathrm{HL}$ & 5 & $8.54 \pm 3.27$ & 16721.5 & $1 \times 10^{-4}$ \\
\hline JG & 10 & $13.55 \pm 4.48$ & 11405.5 & $1 \times 10^{-4}$ & $\mathrm{GC}^{\Delta}$ & 10 & $8.05 \pm 3.17$ & -7165 & $1 \times 10^{-4}$ \\
\hline DG & 12 & $19.07 \pm 8.34$ & 19188.5 & $1 \times 10^{-4}$ & $Z_{G C}^{* \Delta}$ & 10 & $9.78 \pm 4.73$ & -1228.5 & 0.114 \\
\hline $\mathrm{CH}^{\square}$ & 10 & $15.06 \pm 6.51$ & 13545 & $1 \times 10^{-4}$ & $\mathrm{MH}^{\Delta}$ & 10 & $7.29 \pm 2.71$ & -9971.5 & $1 \times 10^{-4}$ \\
\hline $\mathrm{BS}^{\square}$ & 15 & $23.39 \pm 13.06$ & 10478 & $1 \times 10^{-4}$ & $\mathrm{ZMH}^{\Delta}$ & 10 & $8.50 \pm 2.73$ & -5536.5 & $1 \times 10^{-4}$ \\
\hline $\mathrm{CS}$ & 12 & $17.56 \pm 12.78$ & 17148 & $1 \times 10^{-4}$ & $\mathrm{X} R^{\Delta}$ & 10 & $10.65 \pm 2.55$ & 2381.5 & $1 \times 10^{-4}$ \\
\hline $\mathrm{DS}^{\Delta}$ & 30 & $25.48 \pm 12.22$ & -4545 & $1 \times 10^{-4}$ & $\mathrm{SSG}^{\Delta}$ & 60 & $22.60 \pm 10.90$ & -22271 & $1 \times 10^{-4}$ \\
\hline $\mathrm{RS}^{\square}$ & 9 & $16.38 \pm 9.70$ & 18624.5 & $1 \times 10^{-4}$ & $\mathrm{DH}^{2 \Delta}$ & 15 & $9.17 \pm 3.67$ & -18080.5 & $1 \times 10^{-4}$ \\
\hline $\mathrm{THF}^{\Delta}$ & 15 & $19.30 \pm 7.55$ & 7629 & $1 \times 10^{-4}$ & $\mathrm{SDH}^{2 \Delta}$ & 15 & $10.69 \pm 4.17$ & -14689 & $1 \times 10^{-4}$ \\
\hline MDP & 12 & $15.00 \pm 4.62$ & 14131.5 & $1 \times 10^{-4}$ & $\mathrm{ZS}^{\Delta}$ & 10 & $11.14 \pm 2.92$ & 3420.5 & $1 \times 10^{-4}$ \\
\hline$Z X^{\square}$ & 10 & $16.65 \pm 7.37$ & 16044.5 & $1 \times 10^{-4}$ & $\mathrm{HP}^{\Delta}$ & 10 & $11.54 \pm 3.35$ & 4534 & $1 \times 10^{-4}$ \\
\hline LG & - & - & - & - & & & & & \\
\hline
\end{tabular}

Note: indicates no statistical difference; ${ }^{\Delta}$ indicates the medians of Chinese herbs are less than or equal to the ULV of those in pharmacopeia; ${ }^{\square}$ indicates $5 \mathrm{~g}$ more than the ULV stipulated in pharmacopeia compared with the corresponding median; ULVSP =Upper limit value stipulated in pharmacopeia

Table 4: Proportion of TCM doctors' single herb dose that exceeds pharmacopeial dose

\begin{tabular}{lccccccc}
\hline $\begin{array}{l}\text { Chinese } \\
\text { herb }\end{array}$ & $\begin{array}{c}\text { PHDEUL } \\
\text { VSP (\%) }\end{array}$ & $\begin{array}{c}\text { Chinese } \\
\text { herb }\end{array}$ & $\begin{array}{c}\text { PHDEULVSP } \\
(\%)\end{array}$ & $\begin{array}{c}\text { Chinese } \\
\text { herb }\end{array}$ & $\begin{array}{c}\text { PHDEUL } \\
\text { VSP (\%) }\end{array}$ & $\begin{array}{c}\text { Chinese } \\
\text { herb }\end{array}$ & $\begin{array}{c}\text { PHDEULVSP } \\
(\%)\end{array}$ \\
\hline $\mathrm{ZFZ}$ & 13.907 & $\mathrm{ZM}^{\circ}$ & 62.71 & $\mathrm{SZR}^{\circ}$ & 65.35 & $\mathrm{WZY}^{\bullet}$ & 88.04 \\
$\mathrm{XX}^{\circ}$ & 66.556 & $\mathrm{MD}^{\circ}$ & 84.82 & $\mathrm{ZL}^{\circ}$ & 70.43 & $\mathrm{GG}$ & 22.77 \\
$\mathrm{GJ}$ & 37.748 & $\mathrm{FF}^{\circ}$ & 65.35 & $\mathrm{CX}^{\circ}$ & 71.28 & $\mathrm{HQ}^{2}$ & 41.91 \\
$\mathrm{SJ}$ & 44.37 & $\mathrm{WWZ}^{\circ}$ & 95.05 & $\mathrm{HQ}^{1}$ & 42.57 & $\mathrm{HL}^{\circ}$ & 82.18 \\
$\mathrm{GZ}^{\circ}$ & 52.47 & $\mathrm{JG}^{\circ}$ & 65.02 & $\mathrm{ZHQ}^{\circ}$ & 28.05 & $\mathrm{GC}$ & 8.28 \\
$\mathrm{BZ}^{\circ}$ & 87.13 & $\mathrm{DG}^{\circ}$ & 84.82 & $\mathrm{FL}^{\circ}$ & 60.07 & $\mathrm{ZGC}$ & 21.45 \\
$\mathrm{LQ}^{\circ}$ & 33.66 & $\mathrm{CH}^{\circ}$ & 72.94 & $\mathrm{SM}^{\circ}$ & 44.88 & $\mathrm{MH}$ & 3.78 \\
$\mathrm{TR}^{\circ}$ & 69.64 & $\mathrm{BS}^{\circ}$ & 61.72 & $\mathrm{DH}^{1 \circ}$ & 61.39 & $\mathrm{ZMH}$ & 10.00 \\
$\mathrm{BX}^{\circ}$ & 91.75 & $\mathrm{CS}^{\circ}$ & 74.26 & $\mathrm{SDH}^{1 \circ}$ & 68.65 & $\mathrm{XR}$ & 27.82 \\
$\mathrm{ZBM}^{\circ}$ & 72.94 & $\mathrm{DS}^{\circ}$ & 8.25 & $\mathrm{SG}^{\circ}$ & 53.82 & $\mathrm{SSG}$ & 0.66 \\
$\mathrm{HB}^{\circ}$ & 57.76 & $\mathrm{RS}^{\circ}$ & 88.08 & $\mathrm{HS}^{\circ}$ & 29.67 & $\mathrm{DH}^{2}$ & 2.65 \\
$\mathrm{ZZ}^{\circ}$ & 69.97 & $\mathrm{THF}^{\circ}$ & 48.84 & $\mathrm{ML}^{\circ}$ & 10.56 & $\mathrm{SDH}$ & 4.33 \\
$\mathrm{GL}^{\circ}$ & 51.48 & $\mathrm{MDP}^{\circ}$ & 66.01 & $\mathrm{FJ}^{\circ}$ & 64.24 & $\mathrm{ZS}$ & 32.34 \\
$\mathrm{QP}^{\circ}$ & 41.39 & $\mathrm{ZX}$ & 81.52 & $\mathrm{YC}^{\circ}$ & 70.19 & $\mathrm{HP}$ & 39.60 \\
\hline
\end{tabular}

indicates Chinese herbs prescribed by $>50 \%$ of the selected TCM doctors who exceeded ULVSP; ${ }^{\bullet}$ indicates Chinese herbs prescribed by $>80 \%$ of the selected TCM doctors who exceeded ULVSP 
Table 5: Ranking of factors influencing factors on dose-effect relationship, by TCM doctors

\begin{tabular}{|c|c|c|}
\hline Factor & $\begin{array}{l}\text { Total } \\
\text { points }\end{array}$ & Rank \\
\hline $\begin{array}{l}\text { Variety and quality of Chinese } \\
\text { herbs }\end{array}$ & 2377 & 1 \\
\hline Preparation & 1982 & 2 \\
\hline $\begin{array}{l}\text { Severity of main and minor } \\
\text { syndromes }\end{array}$ & 1476 & 4 \\
\hline Herbal combination & 1820 & 3 \\
\hline Region-season-climate & 1085 & 7 \\
\hline Constitution & 1313 & 5 \\
\hline Doctor's reputation & 389 & 8 \\
\hline Decocting method & 1135 & 6 \\
\hline Other & 38 & 9 \\
\hline
\end{tabular}

quality of Chinese herbs, preparation method, and herbal combination.

With regard to the reasons for the adoption of higher dosage of prescribed Chinese herbs, almost $90 \%$ TCM doctors believed it was closely related to the poor quality of current medicinal materials, which is correspondent with variety and quality of Chinese herbs ranked first in influencing factors of dose-effect. In recent years, with increased demands on medicinal materials due to the advancement of the herbal industry, natural crude ones invariably fall short of the market's requirement resulting in the extensive artificial planting and cultivation of Chinese herbs. The effective constituents of artificial medicinal materials are substantially lower than natural ones. This is the general consensus of the majority of TCM doctors. For instance, the contents of volatile oil and saponin in wild $\mathrm{CH}$ were higher than those in the cultivated ones [9]. With regard to the preparation of Radix Morindae officinalis (Ba Ji Tian, BJT) as an example and due to the core of BJT with a large proportion can't be selected as an herb. If it is not removed, it will reduce the efficacy due to the insufficient dosage of the essential ingredients of BJT and this has been verified by modern research. It was reported that differences of the chemical components in root bark and core were significant. The content of lead in root bark was less than that in the core, but contents of 16 trace elements like iron, manganese, and zinc, etc. were higher in root bark in comparison with those in the core [10]. In comparisons to the processed Chinese herbs like SDH2, rhubarb charcoal (Da Huang Tan, DHT), and DH2, the total amount of anthraquinone glycoside as a main component of purgation decreased by 55 and $95 \%$, respectively compared with that in the $\mathrm{DH} 2$. On the contrary, the total amount of anthraquinone aglycone in $\mathrm{SDH} 2$ and DHT increased by $75 \%$ and $46 \%$. Besides, the content of gallic acid in SDH2 and DHT remarkably increased, which was 2.4 times and
1.3 times of that in $\mathrm{DH} 2[11]$. The above two examples indicated different preparations of the same Chinese herbs could lead to varied effects. When broaching on the subject of herbal combination as an influencing factor on doseeffect relation, most of the TCM experts agree on this issue. The first existing clinical classic, Treatise on Cold Damage and Miscellaneous Diseases (Shang Han Za Bing Lun) [12], characterized by compact Chinese herbs with remarkable efficacy, and precise and appropriate in herbal combination which is highly praised and followed by TCM doctors of later generations.

The proportion of Rhizoma atractylodis (Cang Zhu, CZ) and $\mathrm{MH}$ in combination summarized by the late TCM practitioner Xu Gongyan [12] was representative. He said if the two herbs with equal dose, profuse sweat could be seen in clinic; if dosage of $\mathrm{CZ}$ was 2 times that of $\mathrm{MH}$, slight sweat could be promoted; if dosage of $\mathrm{CZ}$ was 3 times that of $\mathrm{MH}$, the effect of promoting urination was remarkable; if dosage of $\mathrm{CZ}$ was 4 or 5 times that of $\mathrm{MH}$, though effects of promoting sweating and urination were not so obvious, yet damp pathogen could be transformed (ascribed to the effect of drying damp by $C Z$ ) [12]. What's more, an experiment was accomplished to discuss the tranquilizing effect of Jiaotai pill only containing two Chinese herbs, HL and Cortex cinnamomi (Rou Gui, RG) in different ratios of $10: 1,3: 1$, and $1: 1$ by evaluating the following 3 aspects: synergistic effect on pentobarbital sodium, influence on mouse's locomotor activity, and impact on central neurotransmitter. After comparison, the ratio of 10:1 in $\mathrm{HL}$ and $R G$ in the original formula could obtain an optimal effect, which proved rationality in herbal combination of Jiaotai pill [13]. Therefore, TCM doctors attach great importance to the herbal combination in clinic.

In addition, other influencing factors such as constitution and decoction method, etc, also have significant impact on dose-effect relationship and as such should be factored in when deciding on dosage in clinical practice.

Pharmacopoeia is a code recording standard specifications of drugs and Chinese herbs compiled by China Pharmacopoeia Committee and promulgated and executed by our government with legal implications. The role of China Pharmacopeia is to stipulate specifications/standards of quality and varieties of Chinese herbs without imposing specific restrictions on prescribing by TCM doctors in clinical practice. In addition, with reference to European Pharmacopoeia, United States Pharmacopeia, and British Pharmacopoeia, there 
are no specific regulations on doses of drugs prescribed by physicians; instead there are some guidelines on the prescription of drugs [14]. It is suggested that the regulations on dosage of prepared Chinese herbs in China Pharmacopoeia should be listed in clinical medicine guidelines of the People's Republic of China. If this is done, this can improve the quality and authority of the pharmacopoeia.

\section{Limitations of the study}

Individual treatment in a clinic may have led to discrepancies in the collected data which would not otherwise show in a normal distribution. Furthermore, although a multi-stage randomized questionnaire was used in the study, the number of TCM doctors meeting the criteria in some hospitals was limited leading to a reduction of the sample size to a lower one that was originally planned. A larger sample size with regard to dose-effect relationship of Chinese herbal medicines should be used in a future study in order to enrich collected data and possibly confirm our conclusions.

\section{CONCLUSION}

The dose criteria in China Pharmacopoeia 2010 are not comprehensive enough, and still show a significant variation from those used by TCM doctors in clinical practice. this variation has been ascribed mainly to the poor quality of the Chinese herbs, poor method of preparation, and inappropriate herbal combination. It is clear that the doses of some Chinese herbs are intentionally or randomly increased by TCM doctors.

\section{ACKNOWLEDGEMENT}

This study was supported by The National Basic Research Program of China (973 Program, No. 2010CB530604). The first two authors, Shenglou $\mathrm{Ni}$ and Chuan-Rong Chen, contributed equally to this work, and should be considered co-first authors.

\section{REFERENCES}

1. Fan JJ, Cao LG, Wu T, Wang DX, Jin D, Jiang $S$, Zhang $X Y, B i L, P e i G X$. The dose-effect of Icariin on the proliferation and osteogenic differentiation of human bone mesenchymal stem cells. Molecule 2011; 16: 10123-10133.

2. Fu YL, Cai KZ, Song J. Documentary and theoretical researches about medicinal dose-effect relationship in TCM formulas. J Beijing Univ Tradit Chin Med 2010; 33: 601-605.

3. He LF. Discussion on comprehensive application of multistage sampling in medical investigation. Mark Res 2010; 5: 32-34.

4. He SM. Chinese herbal dose in ancient and modern times: a comparative study. J Tradit ChinMed 2013; 33: 268-271.

5. Ji RL, Xia SH, Di Y, Xu W. Mechanism and dose-effect of Ginkgolide $B$ on severe acute pancreatitis of rats. World J Gastroenterol 2011; 17: 2241-2247.

6. Li L, Xiao YQ. Study on the variation rules of material basis of Rhubarb after processing. China JTradit Chin Med Pharm 2012; 27: 803-813.

7. Lu F, Liu SM, Wang R, Liu CF. Association study of dose-effect in lung heat pattern treated by Radix Scutellariae. Acta Chin Med Pharmacol 2011; 39: 69.

8. Murtaza M, Karim S, Akram MR, Tariq I, Khan SA, Azhar S, Nazar HMI, Farzana K, Mumtaz A, Asad MHHB. Caffeic acid phenethyl ester and therapeutic potentials. BioMed Res Int 2014; Article ID 145342, http://dx.doi.org/10.1155/2014/145342.

9. Qin $H Z$, Liu L, Wang $X Q, Y u T F$, Liu Y. Reflection on dosage of the Chinese herbs and dose-effect relation. J Sichuan Tradit Chin Med 2011; 29: 48-49.

10. Tang SH, Chen JX, Wang YP, Wang L, Yang HJ. Research ideas and strategies on the dose-effect relationship of traditional Chinese medicine prescriptions and herbs. J Tradit Chin Med 2012; 32: 110-113.

11. Shi C, Karim S, Wang C, Zhao M, Murtaza G. A review on antidiabetic activity of Citrullus colocynthis schrad. Acta Pol Pharm Drug Res 2014; 71: 363-367.

12. Tong $X L$, Zhao LH, Lian FM, Zhou Q, Xia L, Zhang JC, Chen $X Y$, Ji HY. Clinical observations on the doseeffect relationship of Gegen Qin Lian Decoction on 54 out-patients with type 2 diabetes. J Tradit Chin Med 2011; 31: 56-59.

13. Liu T, Zhen J, Yu H, Zhang W, Li X, Lv G, Murtaza G, Gu $X$. Effective chemical constituent's identification of extracting solution from herbs - a review. Afr J Tradit Complement Altern Med 2014; 11: 53-69.

14. Duan J, Zheng C, Gao K, Hao M, Yang L, Guo D, Wu J, Tian Y, Song X, Liu J, Guo S, Murtaza G, Zheng M. Ultrasonography of lower limb vascular angiopathy and plaque formation in type 2 diabetes patients and finding its relevance to the carotid atherosclerotic formation. Pak J Med Sci 2014; 30: 1-5. 